from this flame is thrown by a parabolic mirror on a selenium cell which is attached to a galvanometer. The deflections of the needle of the galvanometer therefore show the changes in the volume of blood in the skin. These changes may be recorded in a smoked drum by having the electric current connected through a solenoid with a recording needle.

3. The Measurement of the Electromotor Changes in the Fingers.This part, like the former two, is taken up mostly with the description of an apparatus consisting in the main of two electrodes on which the hands or fingers are rested and which are in circuit with a mirror galvanometer. The author concludes that the electromotor processes are stronger in the fingers than in the palm of the hand. These results are largely the effects of muscular contraction and in so far as they represent involuntary movements of expression they can be said to be an electromotor end result of a psychophysical process. WM. A. White (Binghamton, N. Y.).

\title{
VOPROSSY NERVON-PSYCHICHESSKOY MEDITZINY
}

$$
\text { (January-March, I902.) }
$$

I. Rudolph Virchow. I. Sikorsky.

2. A New Clinical Variety Idiophrenia Paranoides. I. Sikorsky.

3. From the Domain of Psychopathic Literature. P. Preobrajensky.

4. The Pathological Anatomy of the Nerve Cells as Applied to Mental Diseases. I. IvanofF.

5. Paralytic Rabies in Man as Modified by Antirabic Inoculations. I. HMELIEVSKY.

6. Suicide in Keeyeff. N. Oblonsky.

7. Traits of Character and Mimicry in Dementia of Alcoholic Origin. I. SIKORSKY.

x. Biographical Sketch. 2 and 3, Psychopathic Literature.-Two very interesting contributions to the comparatively new study of the subject of psychopathic literature as exemplified by the type of writers whom Lombroso designates as mattoids-graphomaniacs. As is well known these are not all confined in lunatic asylums, and some of them not only occupy a more or less prominent place in certain European literatures, but are proclaimed as heralds of new tendencies hitherto unknown in the world's literature. Sikorsky coins for this class the new term of Idiophrenia (Greek, idios, one's own, peculiar, phrenes, mind), while paranoides points to the presence in these literary decadents of ideas of grandeur in connection with those of persecution so characteristic of paranoia, which these cases simulate very closely. The subjoined examples of some of the degenerate scribbling show clearly how perfectly sane and eminently intelligent critics may be betrayed into taking very seriously, senseless inanities of diseased minds that are dished out before the gullible public as the brilliant scintillations of the "moderns," the "symbolists," and similar rubbish.

4. Pathological Anatomy of the Nerve Cells.-A history of the inception and development of the various methods employed in the study of the nervous system.

5. Modified Rabies.-As based upon investigations of his own cases and those found in the literature of the subject, the author draws the following conclusions: (I) There is at times observed in persons bitten by mad dogs and treated afterward by Pasteur inoculations, a peculiar affection of the nervous system with the predominance of symptoms of meningomyelitis in the thoracic or lumbar portions of the cord. (2) This affection bears the character of an infectious disease, as it is usually accompanied by a rise of temperature, at times by respiratory disturbances, and frequently by paralysis of the facial and oculomotor nerves; its duration is from one and a half weeks to two months, always terminating favorably. 
Its clinical history, its course and the analysis of the etinlogical data do not permit of its being classified with any known variety of meningomyelitis. (4) "The picture of the disease corresponds exactly with that of the paralytic variety of rabies in man. (5) In view of the above and also because of the common etiological factor we may assume with a great degree of certainty that we have here to deal with a paralytic, being a form of rabies which becomes considerably weakened in its intensity by the aid of antirabic inoculation.

6. Suicide in Keeyeff.-A continued article.

7. Traits of Character and Mimicry in Dementia.-A series of portraits of alcoholic individuals, showing the acquisition of certain characteristic traits undoubtedly due to the abuse of spirits with all its baneful consequences. Considering the prevalence of drunkenness-secret as well as open -this fact is one of immense importance. Many a writer's literary work carries with it the reflection of his spiritual self as influenced by the excessive indulgence in alcohol, and a close study of some of the pearls of the modern literature (special reference is made to the decadent school of writers) reveals a peculiar style which the author justly calls "alcoholic."

9. Psychiatry and Psychology. Zienes.

$$
\text { (April-June.) }
$$

Io. White Dermography. P. Nikolsky.

II. Affection of the Motor Neurone in Tabes. M. LApinsky.

12. A Review of the Institutions for the Care of Insane in Russia. A. Kotzovsky.

9. Psychiatry and Psychology-An historical survey of scientific psychiatry and its intimate connection with experimental psychology.

Io. White Dermography.-It has long been observed by several investigators (Rayer, Käbner and others), that in certain individuals a trifling irritation of the skins causes blushing, which may last for a considerable. time, and Dr. Jardin-Beaumetz has demonstrated a case of a woman on whose skin a phrase could be written which would remain in letters raised above the surface for many hours. In some cases the red color would gradually give way to a white line. a condition somewhat rarer than the former one. The author ascribes this phenomenon to the fact that in white dermographism the vasodilator nerves of the skin are insensible and do not respond readily to irritation, while the vasoconstrictor fibers are strongly and quickly irritated, thus causing contraction of the vessels and pallor of the irritated region. These results of irritation as applied to the skin are observed not only when the irritation is caused mechanically, but also, as verified by the author, when brought about by electricity and heat. Barthelémy found red demographism in epilepsy, hysteria, tabes, gout, exophthalmic goiter, disseminated sclerosis, general paralysis, and also in various skin affections as psoriasis, scleroderma, pityriasis, urticaria and others. As regards white dermography the author thinks it a rule in prurigo, and also in chronic eczema, erythema scarlatiniformum, pemphigus ichthyosis.

II. The Motor Neurone in Tabes.-A continued article.

12. Insane Asylurns in Russia.-A continued article.

\section{(July-September.)}

I5. The Motor Neurone in Tabes.

16. The Insane Asylums in Russia.

17. Multiple Births. A. Inossofr.

18. Suicide in Keeyeff. A. Obolensky.

I5. The Motor Neurone in Tabes.-Some of the results of observations 
and experimental investigations by the author are embraced in the following conclusions: There are cases of tabes in which the motor and trophic affections of the muscles are due not to a neuritis, but to a primary alteration of the cells of the anterior horns of the spinal cord. The following scheme presents the clinical and the pathological differences between the two varieties of tabes:

AMYOTROPHIC TABES WITH AFFECTION OF THE ANTERIOR HORNS.

The paralysis does not correspond with the distribution of the nerve roots. The paralyses and the atrophies are limited to regions connected with certain muscles supplied by certain nerves; within the affected area there may be healthy muscles.

The atrophies and paralyses are asymmetrical.

The affected muscles showed fibrillary contraction.

The pareses and paralyses are preceded by muscular atrophy; it is only with the appearance of the latter that the patient begins to feel weakness.

Electrically there is a quantitative diminution of irritability.

Microscopically we find atrophic changes of individual fibers in the affected nerves and pronounced alterations in the anterior horns.

The motor neurone affection is rather of an atrophic than inflammatory character and its course is subacute.
AMYOTROPHIC TABES OF NEURITIC ORIGIN.

The various paralyses and atrophies are localized in correspondence with the branches of individual nerve roots; both paralysis and paresis are to be found in the area supplied by the affected nerve.

There is a certain symmetry observed in the affected muscles of the various extremities.

No fibrillation in the attacked muscles.

Paralyses appear before atrophies.

There is observed a reaction of degeneration in the affected nerves and muscles.

There are degenerative clianges in the nerve roots, but the anterior horns remain normal.

The affection of the antcrior horns is either diffuse or focal; in this latter we find no typical signs of poliomyelitic anterior; there is no inflammatory condition so characteristic of that diseasc. Both the focal and the diffuse affections may be met with in the samc cord; we find at the same time contracted capillaries, which tend to cause anemia of the anterior horns, limited, however, because of the very small size of the capillaries, at first possibly to individual cells, or small groups of the same; so that the neighboring cells or collections of cells may remain ouite normal and unaffected. The various paralyses, pareses and atrophies and in general the muscular affections of spinal origin originating in a certain segment of the trunk or extremities and accompanied by changes of pain or temperature sense in the corresponding portions of the body must be regarded as segmental affections of the spinal cord; on one hand there were attacked the anterior horns, on the other hand the sensory posterior fibers entering the central gray matter. These so-called "segmental affections" are demonstrable clinically in the simultaneous affection of the motor and sensory spheres of certain parts of the body.

16. The Insane Asylums in Russia.-An historical review and particu- 
lar description of the most prominent insane asylums in Russia.

I7. Multiple Births.-A rather curious attempt to classify multiplicity of births, anthropologically arranged as regards the population of Russia, as one of the symptoms of racial as well as individual degeneration.

I8. Suicide in Keeyeff.-The greatest number of suicides occurred during the hot months of $J$ une and July; this fact goes far toward substantiating the proposition held by many neurologists that high temperature acts as an irritant to the nervous system which frequently results in attempted suicide; it is, however, the barometric pressure that seems to play the most important rôle.

Alex. Rovinsky.

\section{MISCELLANY.}

Reflex Convulsions in Growing Boys and Grrls. E. S. Sinith (Lancet, Jan. 24, I903.)

Convulsive attacks occur in rickety and highly neurotic infants during teething and other reflex irritations. It is not so well known that they also occur as pure reflexes during worry in children about eleven or twelve years old, members of families of distinct neurotic tendencies. There is one symptom in common deserving attention, namely, habitually cold feet in these individuals. It usually provokes little attention, but, if disregarded, may thwart the best cfforts of the physician in treatment. With these cold feet, the child's sensibility to chills is increased. He can offer no effectual resistance to the sudden changes of temperature. Digestive derangement follows, malnutrition, and weakness and injurious tendencies are irritated. The nervous system is then readily thrown off its balance. If such nervous conditions may be controlled in the infant, they certainly may be in the older child. Such nervous scizures are as harmless in the older child as in the younger child, and apparently leave the patient in no worse condition, but there are cases where the condition becomes so chronic and recurrent that hardly any appreciable excitable cause may exist to bring them about. It is therefore advisable that the children should have their health built up, and such sickness and general depression as coldness of the feet should always have attention.

JELLIFFE.

The Patellar Tendon Reflex in Croupous Pneunionia in Children. M. Pfaundler (Münchener med. Woch., I902. Vol. 49, p. I,2rI).

From a study of 200 cases of croupous pncumonia in children Pfaundler found that in 27.5 per cent. the patellar reficx was absent, or diminished. From this study he concludes: (I) As a rule fever was well marked, but the absence of the reflex was noted in certain cases which were at the time non-febrile, and the sign occurred not uncommonly after the crisis, the temperature being nornal or subnormal. (2) It is seen only exceptionally in children over ten years, and rarely in infants at the breast. (3) A relationship between the part affected and the condition of the reflex cannot be made evident. (4) Many of the cases showed severe general symptoms, especially an initial cerebral affection, whilst the mortality ( 5.4 per cent.), was rather high for that age-period. (5) It was particularly met with in strongly built and well-nourished children. (6) The course of the pneumonia in these cases showed no unusual deviation from the normal. (7) Apparently the sign arises early in the discase, and sometimes it was observed when the physical examination of the lung was quite negative. (8) As a rule the reflex returns during or soon after the crisis, and generally, though not always, at the same time on the two sides.

In 87 cases diagnosed as lobular pneumonia Pfaundler found that, excluding one moribund and one doubtful case, the patellar reflex was absent only on two occasions, and diminished on three, and in all of these 